\title{
Characterization of infrared pulses using upconversion
}

\author{
Huot, Laurent; Moselund, Peter M.; Tidemand-Lichtenberg, Peter; Pedersen, Christian
}

Published in:

Proceedings of Mid-Infrared Coherent Sources 2018

Link to article, DOI:

10.1364/MICS.2018.MT1C.3

Publication date:

2018

Document Version

Peer reviewed version

Link back to DTU Orbit

Citation (APA):

Huot, L., Moselund, P. M., Tidemand-Lichtenberg, P., \& Pedersen, C. (2018). Characterization of infrared pulses using upconversion. In Proceedings of Mid-Infrared Coherent Sources 2018 [Paper MT1C.3] Optical Society of America (OSA). Optics InfoBase Conference Papers Vol. Part F87-MICS 2018 https://doi.org/10.1364/MICS.2018.MT1C.3

\section{General rights}

Copyright and moral rights for the publications made accessible in the public portal are retained by the authors and/or other copyright owners and it is a condition of accessing publications that users recognise and abide by the legal requirements associated with these rights.

- Users may download and print one copy of any publication from the public portal for the purpose of private study or research.

- You may not further distribute the material or use it for any profit-making activity or commercial gain

- You may freely distribute the URL identifying the publication in the public portal 


\title{
Characterization of infrared pulses using upconversion
}

\author{
Laurent Huot $^{1,2}$, Peter M. Moselund ${ }^{1}$, Peter Tidemand-Lichtenberg ${ }^{2}$, Christian Pedersen ${ }^{2}$ \\ 1: NKT Photonics, Bregnerødvej 144, 3460 Birkerød Denmark \\ 2: Tehcnical University of Denmark, Frederiksborgvej 399, 4000 Roskilde Denmark \\ lhu@nktphotonics.com
}

\begin{abstract}
We demonstrate and discuss the advantages of a novel system performing time resolved spectral characterization of mid-infrared supercontinuum pulses using electronically synchronized delay-tuned pulsed upconversion.

OCIS codes: (190.7220) Upconversion; (300.6340) Spectroscopy, infrared
\end{abstract}

The use of pulsed mid-infrared sources like supercontinuum sources and quantum cascade lasers is becoming ever more popular in a variety of spectrometric optical systems for detection, identification, and/or quantification of chemical species. It is however critical to characterize their temporal profile as well as the spectral variation within the duration of a pulse to ensure the best possible accuracy, resolution and repeatability of such measurements. This task is complicated as there are to this day no commercial systems available for the characterizing time resolved spectra of mid-infrared sources.

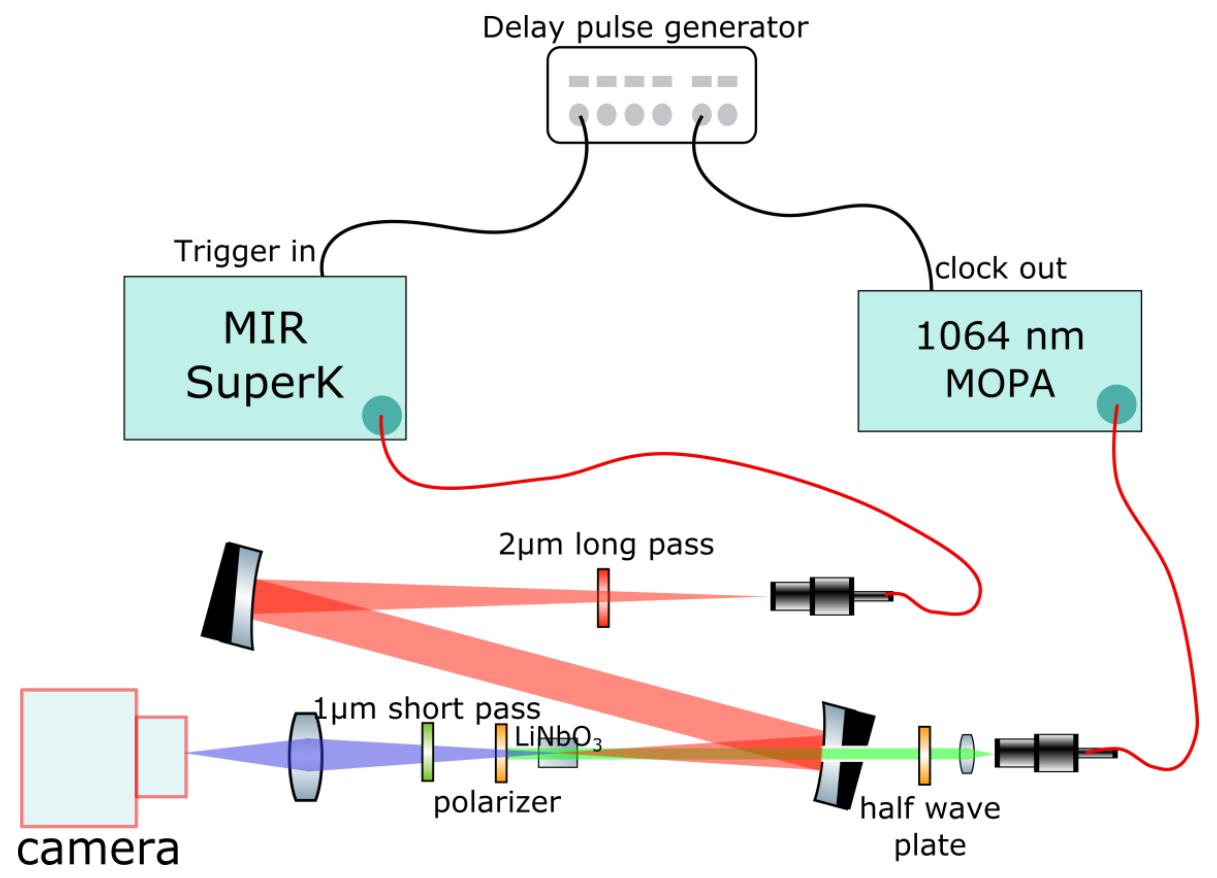

Fig. 1 Schematic of upconversion setup

We present a novel system performing measurements of the temporal profile and time resolved spectra of midinfrared supercontinuum pulses from a Mid-IR SuperK Compact source from NKT using an electronically synchronized and delay-tuned pulsed upconversion setup of which a schematic is presented in fig. 1. The supercontinuum ranges from $2 \mu \mathrm{m}$ to $4.5 \mu \mathrm{m}$ and emits $1.2 \mathrm{~ns}$ pulses at $40 \mathrm{kHz}$ that are focused inside a bulk lithium niobate crystal. In this crystal, the supercontinuum pulses are mixed with sub-200 ps $1064 \mathrm{~nm}$ pulses from a gain switched diode seeded MOPA which acts as the pump for the upconversion process. Both sources are triggered electronically using a T560 pulse delay generator from Highland Technology and their relative delay can be tuned in with a precision of less than $45 \mathrm{ps}$. The temporal and spatial overlap of the supercontinuum and $1064 \mathrm{~nm}$ pulses leads to sum frequency generation in the spectral range of $690 \mathrm{~nm}$ to $860 \mathrm{~nm}$. We characterize the supercontinuum pulses by delay tuning the $1064 \mathrm{~nm}$ pulses and measuring the upconverted signal on a silicon-based camera. The measurements allow us to reconstruct spectrograms as presented in fig. 2. 


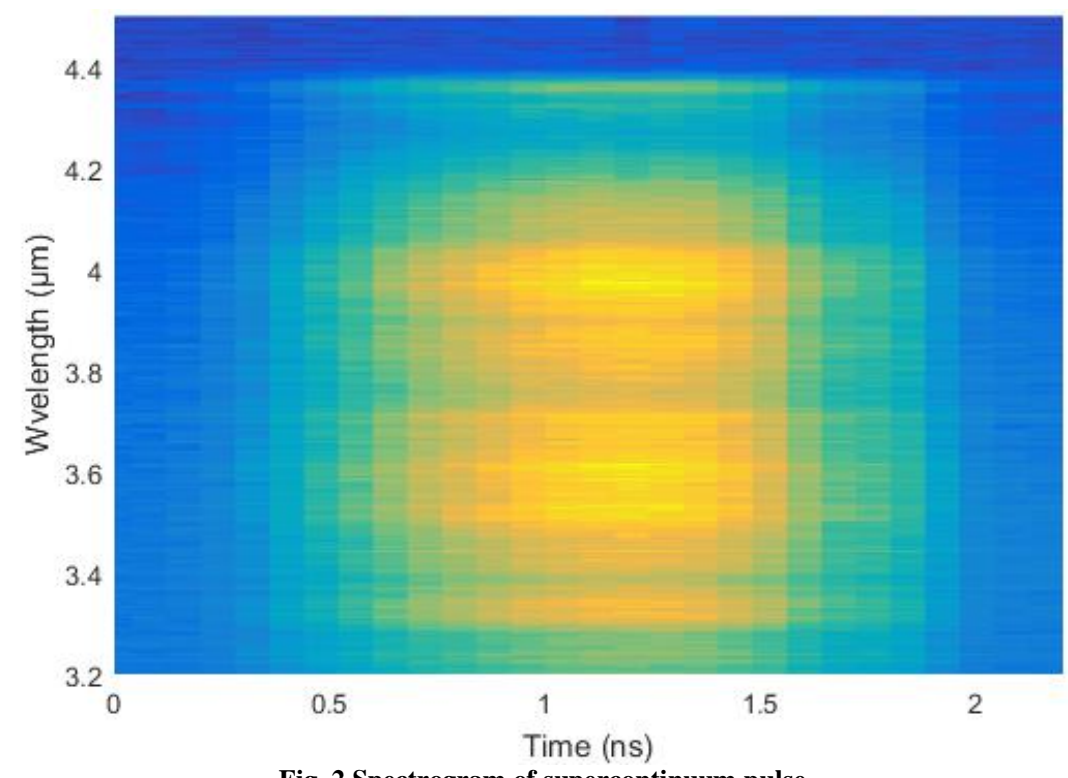

Fig. 2 Spectrogram of supercontinuum pulse

The electronic pulse delay generator has the advantage of not requiring any mechanical delay lines [1]. This is especially an advantage when probing longer timescales i.e. tens of ns or longer as this would require a long delay arm. Additionally, the use of a gain switched diode seeded MOPA enables measurements with temporal jitter 2 orders of magnitude lower than observed in previous similar work [2].

\section{References}

[1] J. Ramsay "Generation of infrared supercontinuum radiation: spatial mode dispersion and higher-order mode propagation in ZBLAN stepindex fibers," Opt. Express 21, 10764-10771 (2013)

[2] J-M. Melkonian "Time-resolved spectral characterization of a pulsed external-cavity quantum cascade lasers", Optics and Photonics for Counterterrorism, Crime Fighting, and Defence VIII, SPIE Proceedings Volume 8546; 854607 (2012); doi: 10.1117/12.971429 